\title{
THE NATIONAL 3-D GEOSPATIAL INFORMATION WEB-BASED SERVICE OF KOREA
}

\author{
D. T. Lee ${ }^{\text {a, }}$, C. W. Kim ${ }^{\text {a }}$ I. G. Kang ${ }^{\text {a }}$
}

\author{
${ }^{a}$ Div. of Geospatial Imagery Information and Photogrammetry, National Geographic Information Institute, \\ Ministry of Land, Infrastructure and Transport Affairs, 443772 Suwon, Korea - (leedt, jumbo, kig777)@ korea.kr
}

Commission II, WG II/2

KEY WORDS: Open platform, 3D modelling, Visualization, Open API, Web-based service, Korean government, 3D application

\begin{abstract}
:
3D geospatial information systems should provide efficient spatial analysis tools and able to use all capabilities of the third dimension, and a visualization. Currently, many human activities make steps toward the third dimension like land use, urban and landscape planning, cadastre, environmental monitoring, transportation monitoring, real estate market, military applications, etc. To reflect this trend, the Korean government has been started to construct the 3D geospatial data and service platform. Since the geospatial information was introduced in Korea, the construction of geospatial information (3D geospatial information, digital maps, aerial photographs, ortho photographs, etc.) has been led by the central government. The purpose of this study is to introduce the Korean government-lead 3D geospatial information web-based service for the people who interested in this industry and we would like to introduce not only the present conditions of constructed 3D geospatial data but methodologies and applications of 3D geospatial information. About 15\% (about 3,278.74 $\mathrm{km}^{2}$ ) of the total urban area's 3D geospatial data have been constructed by the national geographic information institute (NGII) of Korea from 2005 to 2012. Especially in six metropolitan cities and Dokdo (island belongs to Korea) on level of detail (LOD) 4 which is photo-realistic textured 3D models including corresponding ortho photographs were constructed in 2012. In this paper, we represented web-based 3D map service system composition and infrastructure and comparison of V-world with Google Earth service will be presented. We also represented Open API based service cases and discussed about the protection of location privacy when we construct 3D indoor building models. In order to prevent an invasion of privacy, we processed image blurring, elimination and camouflage. The importance of public-private cooperation and advanced geospatial information policy is emphasized in Korea. Thus, the progress of spatial information industry of Korea is expected in the near future.
\end{abstract}

\section{INTRODUCTION}

3D geospatial information systems should provide efficient spatial analysis tools and able to use all capabilities of the third dimension, and a visualization (Losa and Cervelle, 1999). Since the geospatial information was introduced in Korea, the constructions of geospatial information such as 3D data, digital maps, aerial photographs, digital ortho photographs, etc. have been led by the central government. Most of the central and local government's works were changed from paper maps to geographic information systems in recent ten years. But on the other hand, the government has been accused of not responding appropriately to a dramatic change in spatial data industry environments such as appearance of Google Earth. For this reason, the ministry of land, infrastructure and transport (MOLIT) of Korea is moving forward with new geospatial information construction plans.

The purpose of this study is introducing the national lead 3D geospatial information web-based service of Korea for the people who interested in this industry. In this research, we represented 3D geospatial information development methods to enhance web accessibility and utilization. In order to use of geospatial information in national administrative and private industries fields, data sharing attribute and convergence are essential. To solve this problem, The Korean government adopted 3D geospatial information web platform and developed open API. The ultimate goal of this plan is various decision supports in national administrative, business, public activities, etc.

The 3D geospatial information construction paradigm of the Korean government is divided three parts. The first is a creation of the information communication technology (ICT) industry by constructing cyber national geospatial information. National 3D geospatial information can use basic infrastructure to make policies like military application, urban planning, culture \& tourism, location based service, etc. The second is an efficient management of the national geospatial data because 3D geospatial data is an integration of a lot of geospatial data. The third is job creation and revitalization of spatial information industry. Those plans are based on the government's key policy direction of the Park administration.

Formerly, MOLIT has constructed aerial photographs, digital ortho photographs, digital maps, digital elevation models (DEM), digital surface models (DSM), etc. but in recent years, spurs 3D indoor and outdoor geospatial information constructions. MOLIT planned to construct 3D geospatial information in 2003 and started pilot project in 2004. The construction is being continued right up from 2005 to until present day by the National Geographic Information Institute (NGII) of MOLIT. A main characteristic of 3D geospatial

\footnotetext{
* Corresponding author. This is useful to know for communication with the appropriate person in cases with more than one author.
} 
information of Korea is web-based service such as open API which enables to make application programs. It is not to open information simply but to combine with other resources, for example, major portal site can make business models combined with information of the MOLIT to service it.

In this paper, we presented web-based 3D map service system composition and structure. The last part of the paper, V-world open API based application cases and discussions about privacy protection when we construct 3D geospatial data and data integration will be presented.

\section{LITELATURE REVIEWS}

\subsection{D Geospatial Data Modelling}

In the early 1992s, Raper researched about 3D modelling concepts for geoscientific analysis in 1992. He represented a key concept in 3D spatial theory, including those related to data types and dimensions and those related to model building and databasing. Modelling 3D spatial objects in a geo-DBMS using a 3D primitive (Arens et al., 2004) and a simple approach to building a 3D geological model were proposed (Baojun et al., 2004), integrating software packages such as 3D studio max (3DSMax), ArcGIS, and virtual reality modelling language (VRML). An integrated data model in 3D GIS was announced by Zongguo and Jianya in 1999. They represented an integrated data structure including vector and raster data and object oriented data model to represent some irregular spatial 3D objects $(2.5 \mathrm{D})$ such as tunnels. 3D topological modelling and visualization method in an object-oriented database management system was introduced (Losa and Cervelle, 1999).

Kolbe et al. (2005) presented the city generalized mark-up language (GML) as a multi-purpose and multi-scale representation for the storage of and interoperable access to 3D city models in spatial data infrastructure (SDI) in 2005. According to researchers, spatial as well as semantic properties are structured in five consecutive levels of detail, where LOD 0 defines a coarse regional model and the most detailed LOD 4 comprises building interiors resp. indoor features. Included thematic objects, which are especially relevant for disaster management, are different types of DEMs, building features like rooms, doors, windows, and subsurface constructions. Recently, an extended web feature service based 3D GIS architecture was studied from Wuhan University (Wan and Bian, 2007). They investigated the possibilities to public a functional $3 \mathrm{D}$ geo web services platform using OGC specifications for the web feature service and introduced CityGML which is application schema to build $3 \mathrm{D}$ geo-data. They also carried out a prototype environment, to prove the architecture can adequate for access to 3D geo-data. Three years ago, the current web-based 3D city models from openstreetmap (OSM) generation situation in Germany was introduced by Over et al. (2010). Interoperability initiatives of the OGC and possibilities to publish 3D geo-data on the web using OpenGIS compliant web services were researched (de Vries and Zlatanova, 2004). They researched about 3D web mapping prototype environment built to see whether the present OGC specifications are adequate for access to $3 \mathrm{D}$ geo-data (query, visualization, navigation and analysis).

\subsection{D GIS Based Application}

Currently, many human activities make steps toward the third dimension like land use, urban and landscape planning, cadastre, environmental monitoring, transportation monitoring, real estate market, military applications, etc. (Zlatanova et al., 2002).
Nowadays, the service sector of the 3D geospatial information is becoming more expanding over the disaster and accident management fields. A framework for 3D-urban-GIS was introduced (Köninger, 1998). Based on test sites in Rostock and Stuttgart, a 3D-urban-GIS prototype is in development, joining aspects of a 3D-visualization interface and a database for 3D objects. A 3D GIS application over former natural gas storages in coal mines was researched (Kaufmann and Martin, 2008). This model integrates the geological information available and is representative of the geological context. The findings of an investigation into the role and use of landscape visualization software for landscape and environmental planning in Germany and relevant literature and comparable surveys were also presented and reviewed in order to determine the current state of affairs, and the general and international relevance of the results were assessed (Paar, 2006). The survey results showed that $3 \mathrm{D}$ landscape visualization has a positive image in Germany, both among user and non-user groups of visualization tools. About 28 percent of private consultancies and freelance landscape architects, as well as $7 \%$ of public authorities, stated that they already used 3D simulation software. A flood monitoring system website using Google Earth and 3D GIS was announced last year (Chan, 2012) and to provide securities and support for mineral discovery, some researches were also conducted such as urban 3D GIS modelling of terrorism sniper hazards (Vanhorn and Rapids, 2010), 3D GIS as a support for mineral discovery (de Kemp et al., 2011).

\section{METHODOLOGY}

\subsection{Data Construction}

The following diagram is a detailed process of 3D geospatial data construction and conversion (see fig. 1).



Figure 1. A Flowchart of the 3D Geospatial Data Generation and Conversion Process

The 3D spatial data were created using digital maps (version 2.0), aerial photographs, digital elevation models (DEM), digital surface models (DSM), GPS survey results, and so on. The heights of buildings were calculated using DEM and DSM, and aerial images were used to making texture images. In recent year, multi-direction digital camera that produces imagery showing the fronts and sides of buildings and ground location information was used to make precise 3D geospatial data. Aerial photographs were taken by low-flying airplanes, depicting up to 12 oblique perspectives (shot from a 40 degree angles) as well as an orthogonal view of every location flown. Digital maps 
were used to construct attribute and feature data. In order to create 3D geospatial data, a lot of tools are used like Microstation, Autocad, Arcgis, etc.

We concentrated on visualization and services of high precision 3D geospatial data, the developed data were constructed by 3DF-GML format not CityGML in order to minimize the network traffic and observe the standards. The standard data format of Korea is 3-dimensional feature GML (3DF-GML) which is object base GML format which is an application format of GML 3.1 and 3.2 and more concise than GML. 3DF-GML defines basis entity, attribute and relation which intended to help various application field of Korea. A range of the expressions is natural and man-made features like traffic facilities, buildings, water resources, topographies and geometries, topologies, coordinates and so on. The 3DF-GML format can interconvert in keyhole mark-up language (KML), web map service (WMS) web feature service (WFS) formats.

The standard of 3D geospatial data construction and management is controlled by the NGII of Korea and all 3D geospatial data should be created in accordance with standard that incorporates construction methodology, data acquisition, editing, visualization steps, quality controls, etc. The standard datasets are divided into four parts which are traffic, building, water resources and topographic data (see table 1). In order to create high quality $3 \mathrm{D}$ geospatial information, emphasis should be placed on not only the quality of the source image and 3D geospatial model but also the level of visualization, such as level of detail and texturing (Lee et al., 2010).

\begin{tabular}{|c|c|c|}
\hline $1^{\text {st }}$ Class & $2^{\text {nd }}$ Class & $3^{\text {rd }}$ Class \\
\hline \multirow{6}{*}{ Traffic } & \multirow{2}{*}{ Road } & Street, Sidewalk \\
\hline & & Crossroad \\
\hline & Railroad & Railroad \\
\hline & \multirow{3}{*}{ Traffic Facility } & Bridge \\
\hline & & Tunnel \\
\hline & & Other Traffic Facility \\
\hline \multirow{8}{*}{ Building } & \multirow{2}{*}{ Dwelling } & Unit \\
\hline & & Multi-unit \\
\hline & \multirow{6}{*}{ Others } & Government Office \\
\hline & & Industrial \\
\hline & & Cultural/Educational \\
\hline & & Medical/Welfare \\
\hline & & Service \\
\hline & & Others \\
\hline \multirow{4}{*}{ Water Resources } & \multirow{4}{*}{ Water Resources } & River Adjuncts(like Dam) \\
\hline & & Shore \\
\hline & & Embankment \\
\hline & & River Face \\
\hline Topographic & - & - \\
\hline
\end{tabular}

Table 1. Standard Dataset of Korea

The LOD of CityGML is classified 5 steps according to expression detail. LOD 0 describes a regional model, and ending with the fully detailed LOD 4 , which comprises both the exterior and interior modelling of city objects like buildings (Kolbe and Gröger, 2003). Representations differ both with respect to geometry and to semantic structuring. The specific characteristic of LOD is that multiple representations of the same object are simultaneously valid (Kolbe et al., 2005; Gröger et al., 2005). The minimum representation units and standard deviations from LOD 1 to LOD 4 are district, town, block, building, respectively and 2 meters, 1 meter, 0.5 meters, 0.2 meters, respectively. The maximum error tolerances from LOD 1 to LOD 3 are 4 meters, 2 meters, 1 meter, respectively and error occurrence cannot allow in LOD 4. If the width of road is under 0.6 meters, then the feature is represented in the 3D model (LOD 4). All bridges must be represented in LOD 4.

A quality assessment basis is also defined in the standard and to create high quality $3 \mathrm{D}$ geospatial data, we check data integrity, consistency, location precision, omission, etc.

\subsection{Pre-Processing for Web Service}

In order to improve the service speed, some remarkable techniques were applied to V-world. The first is a storage format optimization. Generally, the image resolution is about 4,096 pixels in case of high resolution. Thus, V-world is applied tile map service (TMS) which is a protocol for serving maps as tiles, for example, splitting the map up into a pyramid of images at multiple zoom levels. Because the number of image files is very huge in general, it cannot be served at once in on piece. Users, therefore, should specify which tile they want to see (Kim et al., 2001).
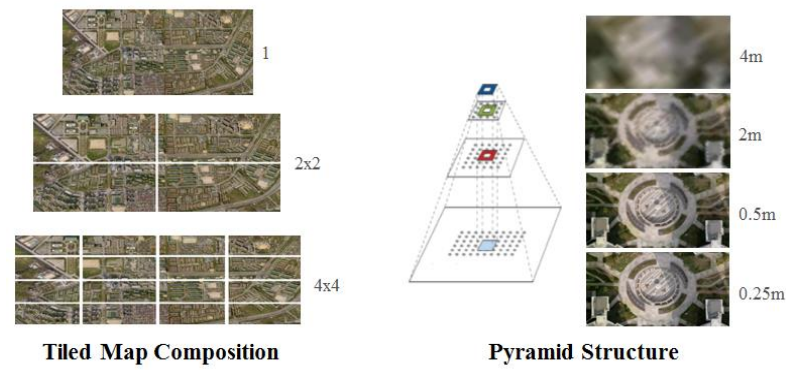

Figure 2. Tiled Map Pyramid Structure

The second method is object split representation method. In case of complicated structure such as islands, arched buildings, it is not easy to represent existing work method because of the limitation of graphic cards or the graphic function of CPU does not support display rotation, thus, we split the images until acceptable limits of graphic devices (see fig. 3). 3D object images were constructed in LOD based (2 5 steps)

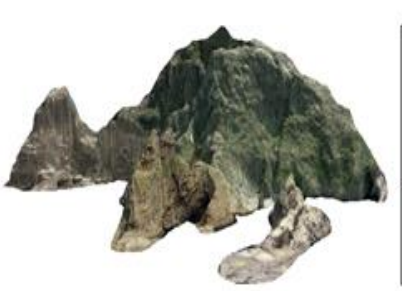

(a)

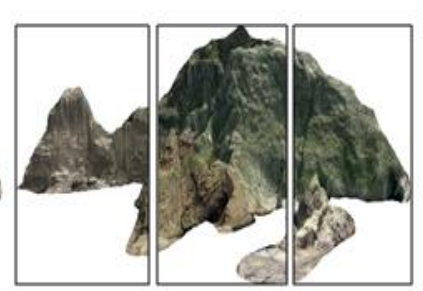

(b)
Figure 3. Representation of Complicated Topography by dividing Images in case of Dokdo (island)

The third is data parallel display which enables to improve display speed by generating thread generation of topography, image, object and texture data (see fig. 4). 


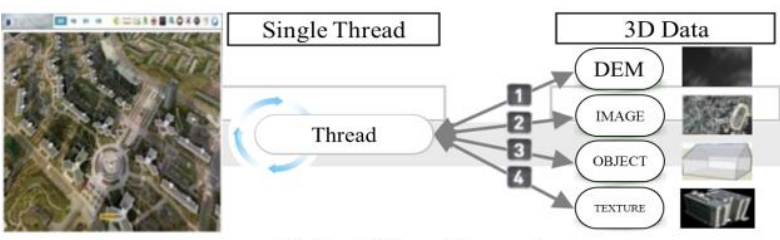

(a) Single Thread Processing

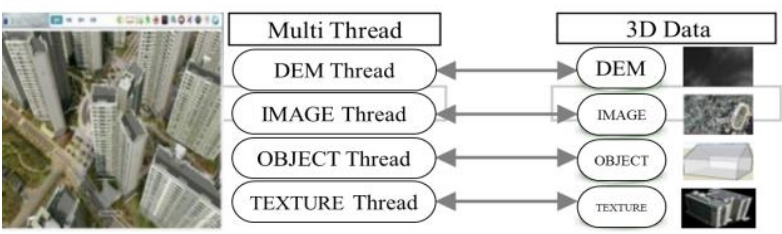

(b) Multi Thread Processing

Figure 4. Comparison of Single Thread Processing with Multi Thread Processing

In order to also improve a service speed, V-world platform supports direct draw surface (DDS) format. To improve availability and support compatibility with the Google maps and Bing maps, aerial photographs and DEMs are served on the NASA world wind map tile formats.

\subsection{Web-Service Framework and Infrastructure}

\subsubsection{Framework}

Constructed 3D geospatial data is provided through the open platform service to the public. Open platform that offers various ways for the using geospatial information available to open and held by MOLIT that has been following rash provision of open platform service ever since 2010 and implemented service in 2012. V-world is an open platform which is based on 3D visual technologies that can show the actual venue in its vivid 3D form, complete with all the exact details. It offers various ways for the using spatial information which are combined on physical database such as roads, buildings, railroads and logical database like administrative boundaries, cadastral maps, etc.

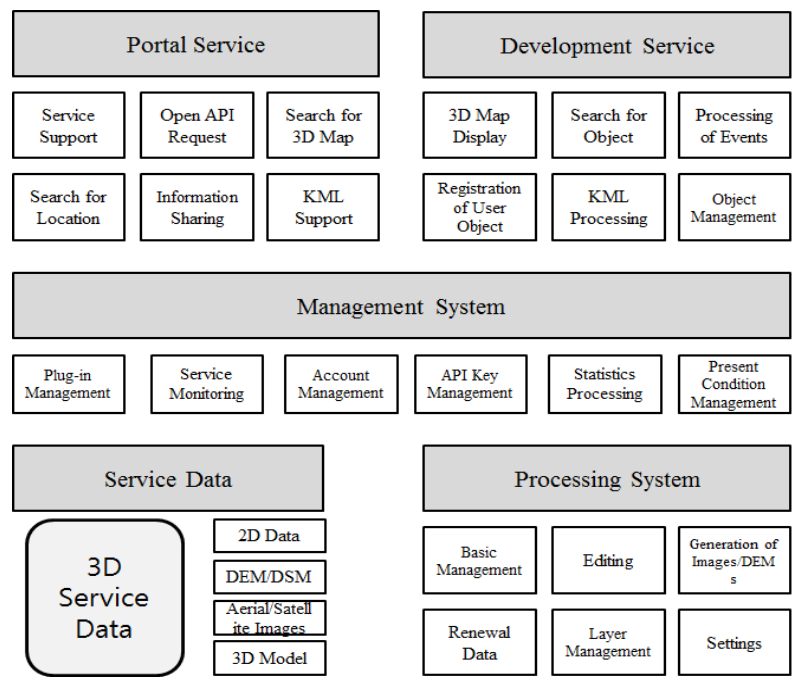

Figure 5. Framework of the Open Platform Service (V-world)
As shown in figure 5, V-world framework is composed of five service and system sectors that are portal service (service support, open API request, 3D map searching, location searching, information sharing, KML support), development service (3D map display, object searching, processing of events, registration of user object, KML processing, object management), management system (plug-in management, service monitoring, account management, API key management, statistics processing, present condition management), service data (2D/3D data), processing systems (basic management, editing, generation of images/DEMs, renewal data, layer management, settings).

\subsubsection{Infrastructure}

In order to serve above various data, a hardware composition is very important. The hardware composition map of geospatial information open platform is as in the following figure 6. A composition of the open platform hardware system is divided with internal and external networks. This enables stable services and data security is tight by double security systems of firewall and web firewall and the L4 load balancing for stateless failover of web connection and server overload protection is one of the characteristics of open platform service. An infrastructure to maintain security is composed with server security, network security, database security and user security. The security method based on the security system that has firewall and web firewall for blocking malicious access to a corresponding network. A server security method is to prevent the outside illegal attack on the main server and the database server. Network security starts with authenticating, commonly with a username and a password. Once authenticated, a firewall enforces access policies such as what services are applied to be accessed by the network users.

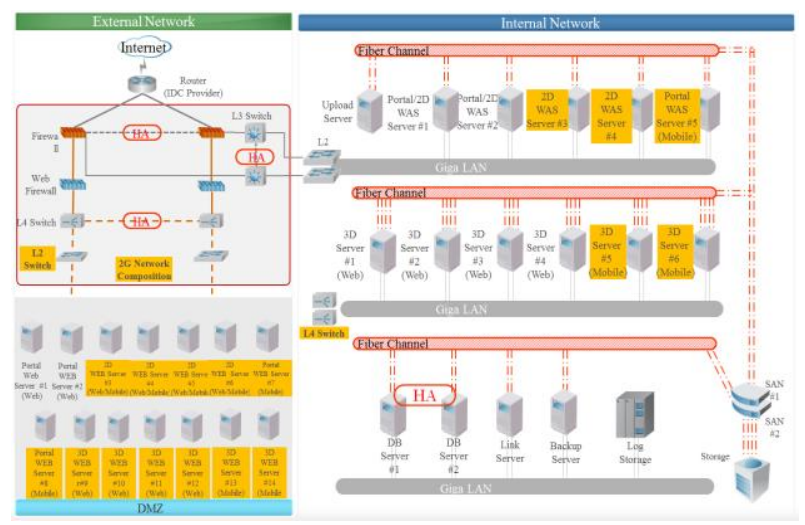

Figure 6. A Composition Map of Open Platform Service

3D geospatial information platform service is composed four parts that are portal, map, data distributions and participation services. Portal and map services support data searching to open platform data and visualization of $3 \mathrm{D}$ geospatial information. A map service system consists of 3D exclusive browser, 3D web browser and 3D mobile browser. A participation service provides a number of utilities for manipulating maps and adding contents to the map through a variety of services. A data distributions service makes available to the public for map or 3D geospatial data for purchase. Hardware and software infra structures for 2D/3D map service, 3D map portal service management, distribution service consist of $3 \mathrm{D}$ web portal server and application portal service, data distributions consist 
of 3D web portal server, web server, DBMS, user interface tools, etc. (see table 2).

\begin{tabular}{|c|c|l|c|}
\hline & Sorts & \multicolumn{1}{|c|}{ Contents } & Q \\
\hline \multirow{7}{*}{ H/W } & $\begin{array}{c}\text { 3D Web } \\
\text { Portal }\end{array}$ & $\begin{array}{l}\text { Install and Management of 3D Web } \\
\text { Portal Service }\end{array}$ & 2 \\
\cline { 2 - 4 } & WAS & Install and Management of WAS & 2 \\
\cline { 2 - 4 } & $\begin{array}{c}\text { 3D Web } \\
\text { Portal DB }\end{array}$ & Management of Attribute Data & 10 \\
\cline { 2 - 4 } & 2D & 2D web GIS Install and Service & 2 \\
\cline { 2 - 4 } & 3D & 3D GIS Server Install and Service & 40 \\
\cline { 2 - 4 } & Distribution & $\begin{array}{l}\text { Management of Distribution } \\
\text { Contents License }\end{array}$ & - \\
\cline { 2 - 4 } & Application & Management of Application Contents & 1 \\
\hline \multirow{5}{*}{ S/W } & Web & 3D Web Portal Service & 2 \\
\cline { 2 - 4 } & WAS & $\begin{array}{l}\text { Web Application Server for 3D Web } \\
\text { Portal Service }\end{array}$ & 52 \\
\cline { 2 - 4 } & DBMS & Management of Attribute Data & 2 \\
\cline { 2 - 4 } & 3D GIS & $\begin{array}{l}\text { 3D Service Provide for 3D Exclusive } \\
\text { Browser }\end{array}$ & 40 \\
\cline { 2 - 4 } & 2D Web GIS & 2D Web Service & 10 \\
\cline { 2 - 4 } & UI Tool & UI Consistency Maintenance & 2 \\
\cline { 2 - 4 } & Reporting & Provide Various Reports & - \\
\cline { 2 - 4 } & $\begin{array}{c}\text { 2D/3D } \\
\text { Processing }\end{array}$ & 2D/3D Data Processing & \\
\hline
\end{tabular}

Table 2. Infrastructure of $\mathrm{H} / \mathrm{W}$ and $\mathrm{S} / \mathrm{W}$

\section{IMPLEMENTATION}

\subsection{Web-based Service Platform (V-world)}

V-world serves that satellite images at 300 meters ground sample distance (GSD) of the world were provided with the national aeronautics and space administration (NASA) and digital ortho photographs of whole country at 0.25 meters and real ortho photographs (some cities) at 0.12 meters were created by NGII of Korea. DEM data of the world at 90 meters are served and 10 meters DEM of whole country and 1 meter DEM of some cities in Korea also derived from NGII. 3D models of buildings, traffic facilities and water resources data of Seoul, Yeosu and Chunchon cities. 2D data such as national boundaries, road networks, subway linemaps, railroad networks, city and country boundaries, building attribute data, etc. are also served in V-world open platform. Currently, the geospatial data of some cities (Pyeongyang, Gaeseong, etc.) of North Korea are also served in V-world. Traffic facilities data such as road networks, railroad networks and information on place name, administrative boundary, etc. are served throughout the country (about $120,000 \mathrm{~km}^{2}$ ). The product of last year was generated using aerial photographs (GSD $8 \mathrm{~cm}$ ) by NGII of Korea and MOLIT has a plan to create indoor and outdoor 3D geospatial information. MOLIT plans to construct until 2016 indoor 3D geospatial information of cultural and public facilities such as Incheon international airport, some subway stations of Seoul, Korea advanced institute of science and technology (KAIST) campus, etc. by developing ITC service and indoor positioning technologies. The created 3D geospatial data are served to the public based on open platform called V-world which is Korean style Google Earth and open API. Many public develop new contents through this service. The buildings and bridges were constructed using pictometry camera and indoor 3D geospatial data are constructing through Indoor GML format using ground light detection and ranging (LiDAR). The 3D indoor service will be soon started (now in progress pilot project).

Figure 7 represent some created results. Figure $7(a)$ is the Dokdo (island) located in North Gyeongsang province of Korea. Dokdo consist of two main islets and 35 smaller rocks and the total surface area of the islets is 0.18745 square kilometres, with the highest elevation of about 169 meters. Figure 7(b) is the Coex located in Seoul city. 2012 Seoul nuclear security summit held at this building, on March 26 and 27, 2012. This cuttingedge service was first used at this event for the purpose of providing security services to the heads of state and government attending the Summit, and since has been drawing acclaim as the next generation core spatial information service. The venue of Yeosu Expo which was used to offer a wide range of benefits, utilizing Korea's cutting-edge geospatial information technologies and IT prowess, so that anyone who has access to the Internet can experience the virtual reality of the 3D rendering of the Expo venues on computer screens. This service enabled the entire 7 billion world population, regardless of their location, be it Antarctica and Africa, could be joined in one unity to be swept away by the wonder of the Yeosu Expo.
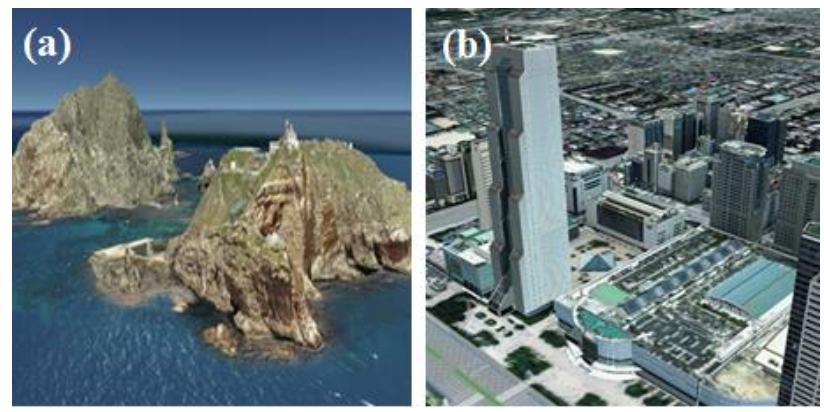

Figure 7. Constructed Data in V-world. (a) shows the Dokdo (island belongs to Gyeongsangbuk-do), (b) Represents the Coex (Seoul)

Figure 8 show that the comparison between $\mathrm{V}$-world and Google Earth services. V-world DEMs and building textures are more precise than Google Earth especially in the banks, hills and buildings. Figure 8 (c-d) shows that the Gherkin building located in London, England.

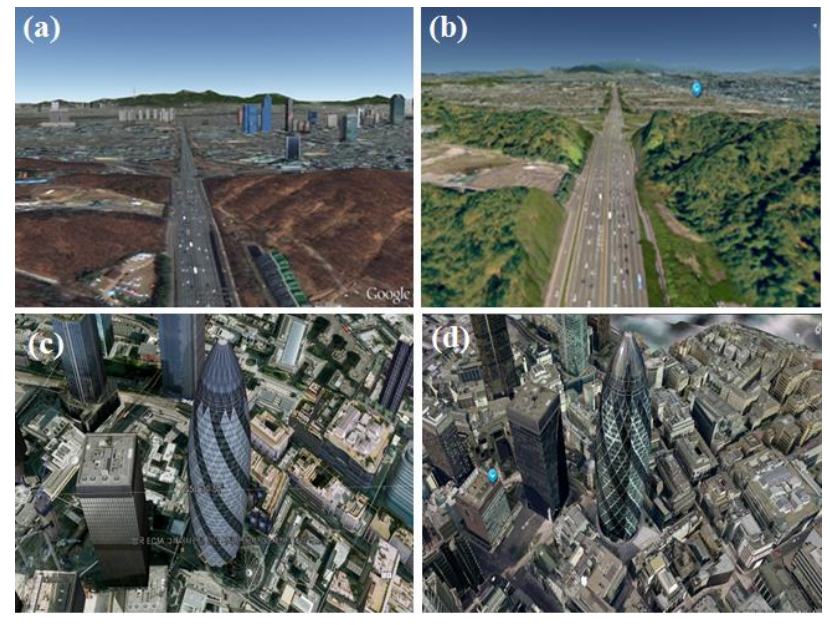

Figure 8. A Comparison of V-world with Google Earth. (a) and (c) Represent the Google Earth Services, (b) and (d) Represent the V-world Services

One of the remarkable services of $\mathrm{V}$-world is $3 \mathrm{D}$ indoor geospatial views. This service is used in evacuation planning, pathfinding service for tourists, etc. and acceptable from inside to outside and outside to inside views (see figure 9 (a) and (b)). 

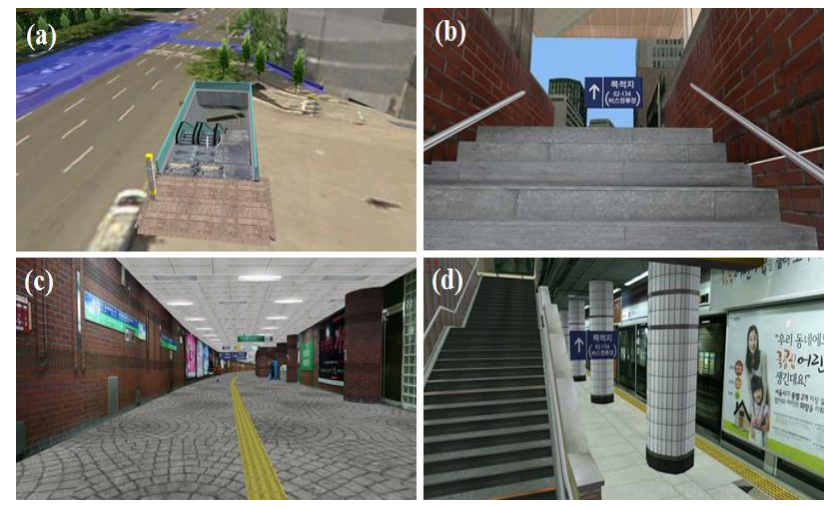

Figure 9. Indoor 3D Geospatial Views in V-world

V-world service based on web, desktop and mobile in 2D and 3D map are already served or will be provided in near future. In particular, a mobile service during this year is being undertaken to enable future, it more users can take advantage of a geospatial open platform is expected (see table 3 ).

\begin{tabular}{|c|c|c|c|c|}
\hline \multicolumn{2}{|c|}{ Device/Media } & 2D & 3D \\
\hline \hline \multirow{4}{*}{ Web } & \multirow{4}{*}{$\begin{array}{l}\text { IE } \\
\text { Plug-in }\end{array}$} & $\begin{array}{c}|c| \\
\text { Chrome } \\
\text { Firefox } \\
\text { Safari }\end{array}$ & \multicolumn{2}{c|}{2013} \\
\cline { 2 - 5 } & \multicolumn{2}{|c|}{ Standard } & 2012.07 & 2014(HTML5) \\
\hline \multicolumn{3}{|c|}{ Desktop } & \multicolumn{2}{c|}{2012} \\
\hline \multicolumn{2}{|c|}{ Mobile } & \multicolumn{2}{c|}{ 2013(come near) } \\
\hline
\end{tabular}

Table 3. Service Situations and Future Plans according to Device and Media

\subsection{Open API based Service of V-world}

One of the reasons of $\mathrm{V}$-world service implementation is to apply mash-up applications. This is to enable the spatial analysis and decision making by private and public spatial information convergence.

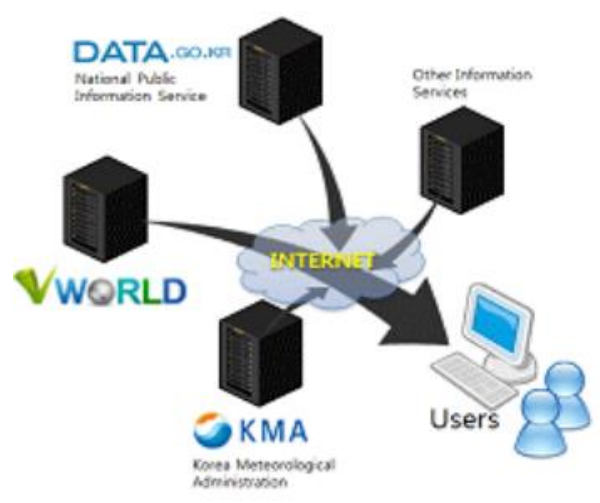

Figure 10. Mash-up Application Model

Some examples of the mash-up applications are as followed in figure 11 and 12. Convergence of landslide risk information from Korea forest service and V-world DEM make it possible to analysis of landslide risk (see figure 11(a)). Since the emergence of laser scanning techniques in the 90's, DEM analysis has increased for landslide studies steadily. This mash- up application case is very useful for decision maker or hillside residents. Figure 11(b) shows the data integration result of serial cadastral map and $\mathrm{V}$-world 3D topographic map. This service is valuable to solve land trouble, to setting-up land boundaries, to establish taxation ranges, etc.
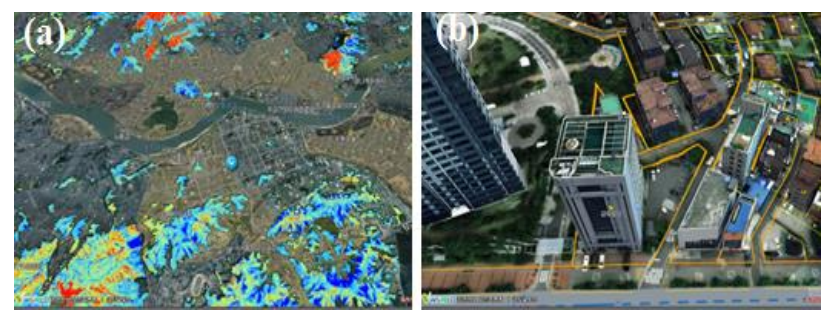

Figure 11. Mash-up Application Cases (1)

The V-world mash-up application is also useful for confirmation of migratory routes and to set up the juvenile protection areas. Figure 12(a) shows that the moving route of the black-faced spoonbill (Korean natural monument number 205). The black-faced spoonbill population as of 2012 census was recorded at 2,693 birds, with an estimation of 1,600 mature birds and conservation efforts are important. Thus, this mash-up application is very useful for preservation of endangered species Figure 12 (b) shows the juvenile protection area setting-up case. The child safety zones' are designated within 200 meter radius from schools. The convergence application of $\mathrm{V}$-world service and juvenile protection information from educational offices is also useful.
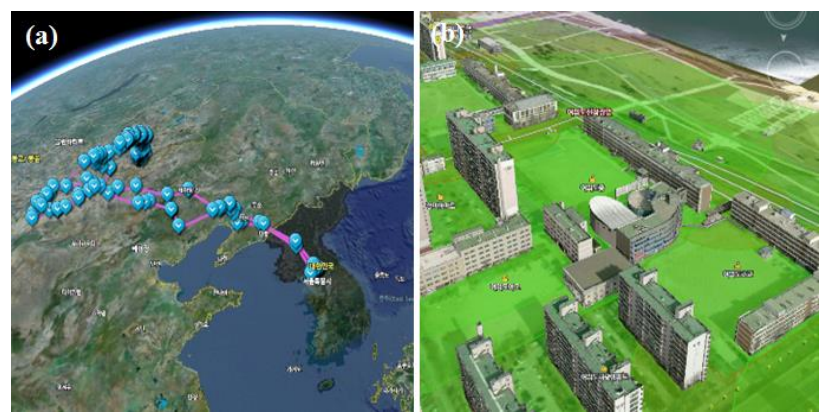

Figure 12. Mash-up Application Cases (2)

\section{CONCLUSIONS}

The Korean government just started to construct the 3D geospatial data and service platform. Since the geospatial information was introduced in Korea, the construction of geospatial information (3D geospatial information, digital maps, aerial photographs, ortho photographs, etc.) has been led by the government. The purpose of this study is to introduce the Korean government-lead 3D geospatial information web-based service for the people who interested in this industry and we introduced not only the present conditions of constructed 3D geospatial data but methodologies and applications of 3D geospatial information. We also represented web-based 3D map service system composition and infrastructure. The last part of the paper, Open API based service of V-world and discussions about privacy protection when we construct 3D geospatial data and data integration were presented. There are a few issues raised in construction of 3D geospatial data. One of the biggest factors is preservation of the privacy of the people. The protection of location privacy when we take pictures in the 
indoor building in order to construct 3D geospatial data is very important. The privacy problem, however, doesn't matter because indoor 3D geospatial information of Korea was mainly constructed in order to use public interest such as disaster prevention, tourism, etc. If the constructed data contain private information, we processed image blurring, elimination and camouflage. Another issue is integration of multi sources of information in the 3D city models. For example, integration of building information models (BIM) and 3D data can be taken into account. The BIM is a process involving the generation and management of digital representations of a facility. Since 3D geospatial information was introduced in Korea, we concentrated on the specific parts such as data construction and high-quality visualization service for the people. So, we didn't consider the integration of BIM in the 3D city models at that time. If the improved geospatial data development structure will be generated, the integration of much information in the $3 \mathrm{D}$ models will be possible.

As rapid progress in the cutting-edge devices such as smart phone, Tablet PC and GPS, etc. and communications technology expands the role of the private sector in geospatial information, many people discussed how to boost cooperation between the public and private sectors. In addition, the importance of public-private cooperation and advanced geospatial information policy is emphasized. Thus, the progress of spatial information industry of Korea is expected in the near future.

\section{REFERENCES}

Chan, Y., 2012, Flood monitoring system website using google earth and 3D GIS, Proc. Of 2012 IEEE International Geoscience and Remote Sensing Symposium(IGARSS), Jul. 2227, pp. 954-957.

Baojun, W., Bin, S., and Zhen, S., 2009, A simple approach to 3D geological modelling and visualization, Bulletin of Engineering Geology and the Environment, 68(4), pp. 559-565.

De Kemp, E. A., Monecke, T., Sheshpari, M., Girard, E. M., Goutier, J. E., Perron, G., and Bellefleur, G., 2011, 3D GIS as a support for mineral discovery, Geochemistry: Exploration, Environment, Analysis, 11, pp.117-128.

De Vries, M., and Zlatanova, S., 2004, Interoperability on the Web: The Case of 3D Geo-Data, IADIS International Conference e-Society 2004, Avila.

Gröger, G., Kolbe, T.-H., Schmittwilken, J., Stroh, V., and Plümer, L., 2005, Integrating versions, history, and levels-ofdetail within a 3D geodatabase, Proc. of the $1^{\text {st }}$ Intern. Workshop on Next Generation 3D City Models, Bonn.

Kaufmann, O., and Marthn, T., 2008, 3D Geological Modelling from Boreholes, Cross-sections and Geological Maps, Appllication over Former Natural Gas Storages in Coal Mines, Computers and Geosciences, 34(3), pp. 278-290.

Kim, Y.-S., Kim, K.-C., Kim, S.-D., 2001, Prefetching Tiled Internet Data using a Neighbor Selection Markov chain, Innovative internet computing systems Lecture Notes in Computer Science, 2060, pp. 103-115.

Kolbe, T.-H. and Gröger, G., 2003, Towards unified 3D city models. In: Schiewe, J., Hahn, M., Madden, M., Sester, M.(eds),
Challenges in Geospatial Analysis, Integration and Visualization II, Proc. of Joint ISPRS Workshop, Stuttgart.

Kolbe, T.-H., Gröger, G., Plümer, L., 2005, CityGMLInteroperable Access to 3D City Models, Geo-information for Disaster Management, pp.883-899

Köninger, A., 1998, 3D-GIS for Urban Purposes, Geoinformatica, 2(1), pp. 79-103.

Lee, H.-J., Ru, J.-H., and Kim, S.-Y., 2010, Quality Analysis of Three-Dimensional Geospatial Information using Digital Photogrammetry, Journal of the Korean Society for Geospatial Information System, 18(4), pp.141-149.

Losa, A., and Cervelle, B., 1999, 3D Topological modelling and visualization for 3D GIS, Computers and Graphics, 23(4), pp. $469-478$

Mäs, S., Reinhardt, W., and Wang, F., 2006, Conception of a 3D Geodata Web Service for the Support of Indoor Navigation with GNSS, Lecture Notes in Geoinformation and Cartography, pp. 307-316.

Over, M., Schilling, A., Neubauer, S., and Zipf, A, 2010, Generating Web-based 3D City Models from OpenStreetMap: The Current Situation in Germany, GeoVisualization and the Digital City - Special issue of the International Cartographc Association Commission on GeoVisualization,34(6), pp. 496507.

Paar, P., 2006, Landscape Visualizations: Applications and Requirements of 3D Visualization Software for Environmental Planning, Computers, Environment and Urban Systems, 30(6), pp. 815-839.

Raper, J. F., 1992, Key 3D Modelling Concepts for Geoscientific Analysis, Three-Dimensional Modelling with Geoscientific Information Systems NATO ASI Series, 354, pp. 215-232.

Vanhorn, J. E., and Rapids, G., 2010, Urban 3D GIS Modeling of Terrorism Sniper Hazards, Social Computer Review, 28(4), pp. 482-496.

Wan, Y., and Bian, F., 2007, An Extended Web Feature Service Based Web 3D GIS Architecture, International Conference on Wireless Communications, Networking and Mobile Computing, Sep. 21-25, pp. 5947-5950.

Zlatanova, S., Rahman, A. A., and Pilouk, M., 2002, Trends in 3D GIS development, Journal of Geospatial Engineering, 4(2), pp. 1-10.

Zongguo, X. and Jianya, G., 1999, An Intergrated Data Model in Three Dimensional GIS, Geo-spatial Information Science, (1), pp. 1-8. 